\title{
Comparison of traditional hand wash with alcoholic hand rub in ICU setup
}

\author{
Mona Maliekal, Nanda Hemvani, Usha Ukande, Sanjay Geed, Maitreyee Bhattacherjee, Julie
} George, D. S. Chitnis

\begin{abstract}
B. Background: Nosocomial infection rate are often higher for intensive care unit (ICU) than other units of hospitals, and hands of health-care workers (HCWs) play a major role in the transmission of the infections.

Aim: To compare the efficacy of conventional hand wash with the hand rub in reducing the transient bacterial flora on the hands of nurses in ICU. Subject and Methods: The 34 nurses posted in our ICU during January-March 2003 were included. A total of 204 samples were collected for the residual bacterial flora on fingers using impression method on MacConkey agar plates. The subjects then used alcoholic hand rub or conventional hand wash and the residual bacterial flora rechecked by testing impression of fingers on MacConkey agar. Results: Escherichia coli, Klebsiella spp., nonlactose fermenting Gram-negative bacilli, staphylococci, and streptococci formed the transient bacterial flora on the hands. Moderate to heavy bacterial density was seen in more than $92.2 \%$ of the hands before washing or hand rub application. Conventional hand wash resulted in drastic reduction in the transient bacterial flora on hands in $50 \%$ cases whereas alcoholic hand rub achieved the effect in $95 \%$ of the samples. Conclusion: Compared with conventional hand wash, alcoholic hand rub is far more efficient in reducing transient bacterial flora on the hands of HCWs and it is more convenient and time saving. It is recommended as a hand hygiene practice in critical areas such as ICU.
\end{abstract}

Key Words: ICU, Hand Wash, Alcoholic hand rub

\section{Introduction}

Nosocomial infection $(\mathrm{NI})$ rates range from $3.5 \%$ to $10 \%$ in general hospital practice and are often greater in intensive care units (ICUs) (15-40\%). ${ }^{[1]}$ The NIs result into complications, increased hospital stay, additional finan-

\section{From:}

Choithram Hospital and Research Centre, Indore, Madhya Pradesh-452014, India

\section{Correspondence:}

Dr. D. S. Chitnis

Head, Infection Control, Departments of Microbiology and Immunology,

Choithram Hospital and Research Centre, Indore, Madhya Pradesh-452014, India. E-mail: ds_chitnis@rediffmail.com cial burden, and increased mortality. The precise prevalence data on NI are lacking for India.

In ICU, the number of direct contacts between the hands of the HCW and the patients are greater, and this leads to increased rate of $\mathrm{NI}^{\left[{ }^{[2]}\right.}$ Hands play a major role in the transmission of blood-borne, enteric, and respiratory-tract infections. The hand hygiene has been considered the most important tool in NI control. ${ }^{[3,4]}$ The bacterial flora on the hands (skin) is differentiated as resident flora and transient flora. ${ }^{[5]}$ The transient flora is responsible for transmission of infection in health-care

Free full text available from www.ijccm.org 
setup and elimination of the same should be the target in hand washing or disinfections practices.

Availability of water for hand washing itself is a problem in some Indian hospitals. Hand drying facility in the form of air-dryer or sterile napkins is more difficult. ICUs are often understaffed and frequent washing and drying could be difficult owing to time constraint as well. Alcoholic hand rubs have been claimed to be more efficient ${ }^{[6]}$ in reducing the microbial flora on the hands.

There is no published data, to our knowledge, on the hand hygiene practice in India. The present study was aimed to assess the transient microbial flora on the hands of the nursing staff in ICU in a tertiary care center and to compare the efficiency of conventional hand washing with alcoholic hand rub in reduction of bacterial flora on the hands.

\section{Study site}

\section{Materials and method}

The Choithram Hospital and Research Centre, Indore, is a 350-bedded tertiary care center. The study was carried out in the ICU of the hospital. The ICU has a medical unit (six beds), a cardiac unit (four beds), and a surgical unit (seven beds).

\section{Subjects and sample collection}

Thirty-four nurses posted in the ICU were included in the study. The hands were checked for the presence of transient bacterial flora during the middle of the routine activities. Periodic random examinations were made by collecting 204 samples during January 2003-March 2003. Obviously, the study included multiple examinations of the ICU nurses.

The sample collection included getting impressions of the fingers of hands on the surface of MacConkey agar plate (100 mm diameter). Two separate plates were used for left and right hand fingers. Following the sample collection, the staff was asked to carry out hand wash or alcoholic hand rubs (alternate basis). After hand washing, the hands were dried using sterile napkins and in case of alcoholic hand rub hands were allowed to airdry. Following the hand wash or alcoholic rub, impressions of fingers were repeated from both the hands on fresh media to check the resident flora.

\section{Hand wash and alcoholic rub}

Standard 30-s hand wash was carried out using Baktolin (Raman and Weil, India) liquid soap. The soap contained lauryl sulfate as detergent, and glycerin and other emollients. The soap dispenser dispensed $0.5 \mathrm{ml}$ per push. The Sterillium (Raman and Weil, India) alcoholic hand rub containing $75 \%$ propanol and a quaternary ammonium compound was used. The alcohol dispenser delivered $3 \mathrm{ml}$ per application.

\section{Bacteriological study}

The MacConkey agar (HI-media, India, Code No. M082) supported the growth of staphylococci, group-D streptococci, and Gram-negative enterobacteria. The plates after finger impressions were incubated at $37^{\circ} \mathrm{C}$ for $24 \mathrm{~h}$ and the colonies identified by Gram's staining and standard biochemical tests. The growth of colonies less than 20 was considered as scanty, whereas colonies 20-100 were reported as moderate growth and greater than 100 as heavy growth. The finger impressions before hand wash or hand rubs were considered as untreated controls.

\section{Ethical issues}

The project was approved by the ethical and research committee and a written informed consent was not suggested by the committee. All the staff members were explained about the study design and were asked to use hand rub or hand wash as they perform routinely.

\section{Statistics}

The selection for a hand rub or a hand wash was on an alternate basis. Differences between bacterial flora before and after hand rub or hand wash were compared using paired $t$-test (microsoft excel).

\section{Results}

The bacterial spectrum of the transient flora on the fingers of the nursing staff in ICU setup is depicted in Table 1. The data show that during the course of routine health-care activities in ICU, both Gram-positive cocci and Gram-negative bacilli get deposited on the hands. A qualitative reduction in the flora occurs after hand washing and a substantial reduction occurred after alcoholic hand rubs.

The transient flora was measured before and after hand 
Table 1: The prevalence and spectrum of bacterial flora on the fingers

\begin{tabular}{lccc}
\hline Organism & $\begin{array}{l}\text { Untreated } \\
\text { hands } \\
(\boldsymbol{n = 2 0 4 )})\end{array}$ & $\begin{array}{l}\text { After hand wash } \\
\text { with and soap } \\
\text { water }(\boldsymbol{n}=\mathbf{1 0 2})\end{array}$ & $\begin{array}{l}\text { Hands after } \\
\text { alcohol hand } \\
\text { rub. }(\boldsymbol{n}=\mathbf{1 0 2})\end{array}$ \\
Staphylococci & 178 & 34 & 7 \\
Group-D streptococci & 12 & 2 & 0 \\
Escherichia coli & 61 & 24 & 2 \\
Klebsiella spp. & 49 & 26 & 3 \\
NLF GNB & 24 & 12 & 1 \\
Spore-bearing bacilli & 71 & 31 & 15 \\
\hline
\end{tabular}

NLF GNB, nonlactose fermenting Gram-negative bacilli. The above data are for qualitative presence of the type of bacteria; the presence of more than one type of bacteria on the hands of a subject was a common observation.

wash or alcoholic hand rubs by a semiquantitative method. The transient bacteria loosely adhered to the finger skin were transferred by a contact of fingers over the solid culture media and a gradation based on the number of colonies was made as shown in Table 2.

The reduction in the transient flora after hand wash was significant $(P=0.01-0.03$ in paired $t$-test). Alcoholic hand rubs drastically reduced the bacterial flora $(P$ $=0.002$ or below).

The effect of hand washing and alcoholic hand rub on the percentage reduction of transient flora is shown in Figure 1 . Only $7-8 \%$ of the persons had nil or scanty growth, whereas $66.7 \%$ had moderate bacterial flora and $25.5 \%$ had heavy bacterial flora on the hands before hand washing or alcoholic hand rubs. The reduction of bacterial flora following alcoholic rub was far greater than after hand wash with soap and water.

\section{Discussion}

Staphylococci are the common organisms responsible for NI. The proportion of NI caused by staphylococci is reported to be $26.4 \%$ among UTI, $23.3 \%$ among septicemia and $12.9 \%$ in lower respiratory tract infection. ${ }^{[7]}$ In the present study staphylococci were grown from 178

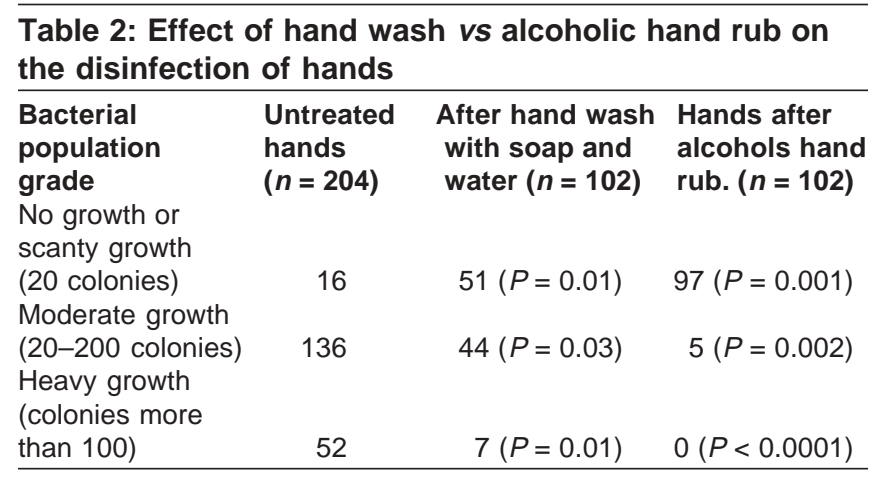

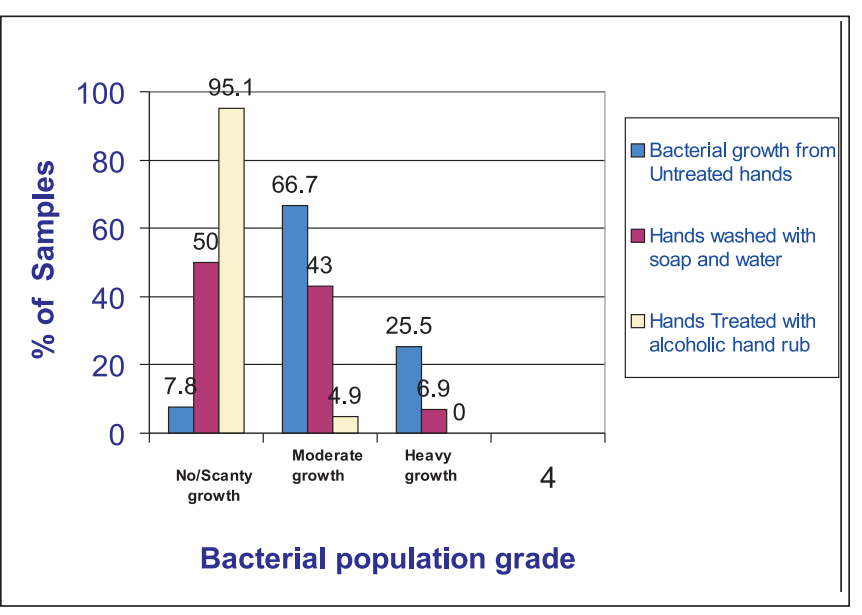

Figure 1: Comparison of bacterial growth from untreated control hands, hands washed with soap and water, and hands treated with alcoholic hand rub

of 204 hand samples collected before hand washing / alcoholic hand rubs. Not mentioned in results but 46 out of 178 staphylococci were coagulase positive Staphylococcus aureus.

The prevalence of NI caused by Gram-negative bacteria has been increasing in ICU setups and it was reported to be as high as $64 \% .{ }^{[8]}$ Transient colonization of Gram-negative bacteria ranges from $21 \%$ to $86 \%$ and the highest rate was noted in ICU. ${ }^{[9]}$ In the present study 134 of the 204 samples collected before washing or alcoholic rub revealed the growth of Gram-negative bacilli. Transient Gram-negative bacteria have been reported to persist in all the 10 health-care workers after washing with soap and water. ${ }^{[10]}$. In the present study, even after the hand wash with soap and water, the Gramnegative bacteria were seen on the hands in more than $50 \%$ of the nurses. The Gram-negative enteric bacteria are resistant to soap or detergents and nonmedicated soap cakes become contaminated and lead to colonization of the hands of personnel and subsequent transmission as NI. ${ }^{[11,12]}$ It needs to be mentioned that soap cakes are still being used in majority of the hospitals and provision of liquid soap dispensers needs to be suggested in the hospital practice.

Repeated application of detergents and soaps results in transepidermal water loss, damage to stratum corneum, and irritative contact dermatitis. ${ }^{[13]}$ Alcohols along with emollients such as glycerin appear to be the safest antiseptic agent for the skin, ${ }^{[14]}$ and the advantage is the fast drying of the alcoholic preparation without the need of a towel. 
The present study clearly documents more efficient reduction of the microbial flora on hands by alcoholic hand rubs in comparison to conventional hand wash. The cost of the alcoholic hand rub is Rs. 1.50 per application whereas the hand wash will be less than Rs. 0.20 per wash. However, the alcoholic rub may not be expensive if the efficiency, side effects, time saved, and mainly the reduction in $\mathrm{NI}$ is considered. We have yet not measured the infection rate as the interventional study. However, the use of alcoholic hand rub practice over a 10-month period reduced $\mathrm{NI}$ by $36 \%$ in a 498 bedded acute care facility ${ }^{[15]}$ and in the other setup by $41 \%{ }^{[16]}$ In the Centers for Disease Control and Prevention guidelines ${ }^{[17]}$ a hygienic hand disinfectant with an alcohol-based hand rub is the preferred treatment of hand hygiene for HCWs and needs to be practiced before and after care of every patient.

\section{Acknowledgment}

We are thankful to the management of the Choithram Hospital \& Research Centre for providing facility for the study.

\section{References}

1. Gastmeier P, Kampf G, Wischnewski N, Schumacher M, Daschner F, Ruden H. Importance of the surveillance method: national prevalence studies on nosocomial infections and the limits of comparison. Infect Control Hosp Epidemiol 1998;19:6617.

2. Fridkin SK, Gaynes RP. Antimicobial resistance in intensive care units. Clin Chest Med 1999;32:873-6.

3. Nystrom B. Impact of hand washing on mortality in intensive care: examination of the evidence. Infec Control Hosp Epedemiol 1994;15:435-6.

4. Reybrouck G. Role of the hands in the spread of nosocomial infections. J Hosp Infect 1983;4:103-10.

5. Pegues DA, Schidlow DV, Tablan OC, Carson LA, Clark NC, Jarvis WR. Possible nosocomial transmission of Pseudomonas cepacia in patients with cystic fibrosis. Arch Pediatr Adolesc Med 1994;148:805-12.

6. Gunter K, Kramer A. Epidemiologic background of hand hygiene and evaluation of the most important agents for scrubs and rubs. Clin Microbiol Rev 2004;17:863-93.

7. Gastmeier P, Sohr D, Geffers C, Nassauer A, Dettenkofer M, Ruden H. Occurrence of methicillin-resistant Staphylococcus aureus infections in German intensive care units. Infection 2002;30:198-202.

8. Richards MJ, Edwards JR, Culver DH, Gaynes RP. Nosocomial infections in medical intensive care units in the United States. National Nosocomial Infections Surveillance System. Crit Care Med 1999;27:887-92

9. Knittle MA, Eitzman DV, Baer H. Role of hand contamination of personnel in the epidemiology of gram-negative nosocomial infections. J Pediatr 1975;86:433-7.

10. Guenthner SH, Hendley JO, Wenzel RP. Gram-negative bacilli as nontransient flora on the hands of hospital personnel. J Clin Microbiol 1987;25:488-90.

11. Grohskopf LA, Roth VR, Feikin DR, Arduino MJ, Carson LA, Tokars Jl, et al. Serratia liquefaciens bloodstream infections from contamination of epoetin alfa at a hemodialysis center. N Engl J Med 2001;344:1491-7.

12. Sartor C, Jacomo V, Duvivier C, Tissot-Dupont H, Sambuc R, Drancourt M. Nosocomial Serratia marcescens infections associated with extrinsic contamination of a liquid nonmedicated soap. Infect Control Hosp Epidemiol 2000;21:196-9.

13. Smit HA, Coenraads PJ, Lavrijsen AP, Nater JP. Evaluation of a self-administered questionnaire on hand dermatitis. Contact Dermatitis 1992;26:11-6.

14. Lubbe J, Ruffieux C, Perrenoud D. A stinging cause for preventive skin care. Lancet 2000;356:768-9.

15. Hilburn J, Hammond BS, Fendler EJ, Groziak PA. Use of alcohol hand sanitizer as an infection control strategy in an acute care facility. Am J Infect Control 2003;31:109-16.

16. Pittet D, Hugonnet S, Harbarth S, Mourouga P, Sauvan V, Touveneau S, et al. Effectiveness of a hospital-wide programme to improve compliance with hand hygiene. Infection Control Programme. Lancet 2000;356:2196.

17. Boyce JM, Pittet D. Guideline for hand hygiene in health-care settings: recommendations of the Healthcare Infection Control Practices Advisory Committee and the HICPAC/SHEA/APIC/ IDSA Hand Hygiene Task Force. Infect Control Hosp Epidemiol 2002;23: S3-S40. 